\title{
Sensitivity of movement and intensity of severe cyclone AILA to the physical processes
}

\author{
S RAmbabu $^{1, *}$, D Gayatri VAni ${ }^{2}$, S S V S RAmakrishna ${ }^{3}$, G V RAma ${ }^{2}$ and B V AppaRAO ${ }^{2}$ \\ ${ }^{1}$ Society for Applied Microwave Electronics Engineering and Research (SAMEER), \\ IIT Campus, Powai, Mumbai 400 0\%6, India. \\ ${ }^{2}$ MET-Facility, Satish Dhawan Space Center, SHAR, ISRO, Sriharikota 524124 , India. \\ ${ }^{3}$ Department of Meteorology and Oceanography, Andhra University, Visakhapatnam 530 003, India. \\ ${ }^{*}$ Corresponding author. e-mail: rametsiri@gmail.com
}

\begin{abstract}
Accurate prediction of movement and intensity of tropical cyclone is still most challenging problem in numerical weather prediction. The positive progress in this field can be achieved by providing network of observations in the storm region and best representation of atmospheric physical processes in the model. In the present study later part was attempted to investigate the sensitivity of movement and intensity of the severe cyclonic storm AILA to different physical processes in the Weather Research and Forecasting model. Three sets of experiments were conducted for convection, microphysics (MP) and planetary boundary layer (PBL) processes. Model-simulated fields like minimum central surface pressure, maximum surface wind, track and vector displacement error are considered to test the sensitivity. The results indicate that the movement of the system is more sensitive to the cumulus physics and the intensity of the cyclone is sensitive to both PBL and cumulus physics. The combination of Betts Miller Janjic (BMJ) for convection, Yonsei University (YSU) for PBL and Purdue Lin (LIN) for microphysics is found to perform better than other combination schemes. The horizontal and vertical features of the system along with its special features like complete northward movement of the system throughout the travel period and the consistent cyclonic storm intensity until $15 \mathrm{hrs}$ after the landfall could be well simulated by the model.
\end{abstract}

\section{Introduction}

Tropical cyclones (TC) are the systems born amid torrential thundershowers and nurtured by water vapour drawn inward from far away due to thermodynamic disequilibria between the warm near surface waters of the tropical ocean and tropospheric column. They are initiated by a large variety of disturbances, including easterly waves and monsoon troughs. From the climatology, Gray (1968) suggested that the greater SST (threshold of 26.5 degree) is highly correlated to the formation of cyclones, but still it is not yet clear why above this threshold value. Once formed, they are maintained by the extraction of latent heat from the ocean at high temperature and heat export to the low temperatures of the tropical upper troposphere as a convective process. This mutual interaction between lower and upper tropospheric phenomenon (conditional instability of second kind) contribute in feeding of energy to the system and intensification from surface low to cyclonic storm.

Keywords. Tropical cyclone; numerical weather prediction; parameterization. 
a)

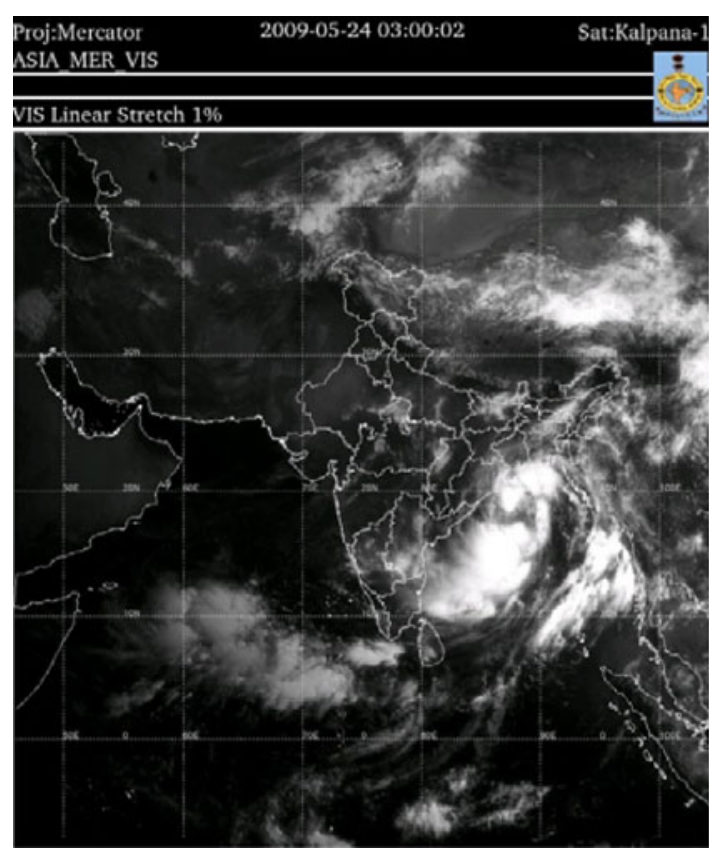

b)

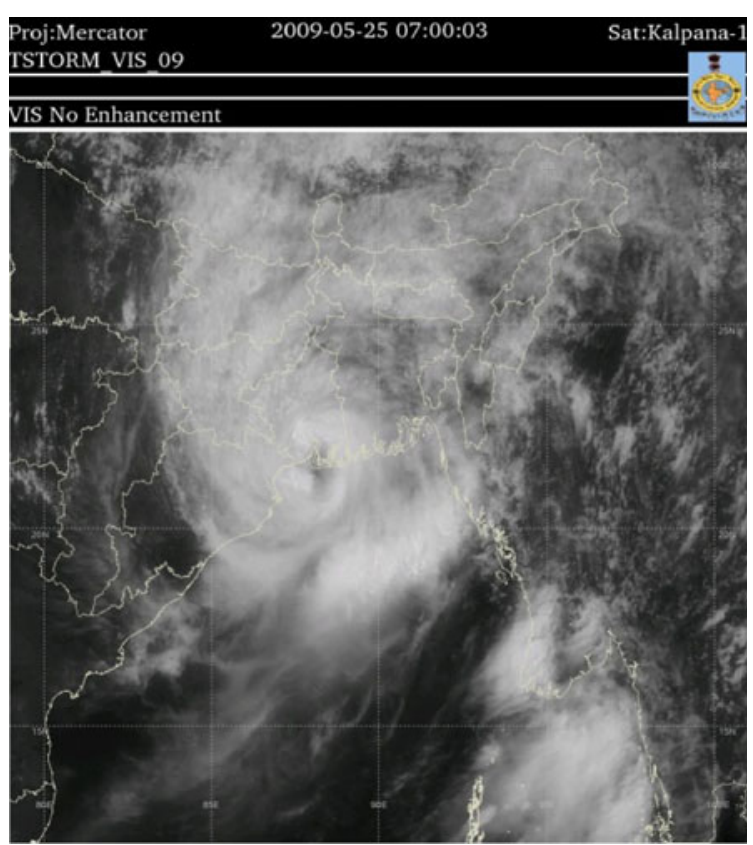

Figure 1. Visible satellite imageries of Kalpana-1 satellite at (a) deep depression stage (24th May 0300 UTC) and (b) severe cyclone storm stage (25th May 0700 UTC).

Table 1. Brief description of WRF model configuration.

\begin{tabular}{ll}
\hline Model & WRF V3.1 \\
Map projection & Mercator \\
Domain & $45^{\circ}-106^{\circ} \mathrm{E} ; 10^{\circ} \mathrm{S}-38^{\circ} \mathrm{N}$ \\
Resolution & $27 \mathrm{~km}$ \\
No. of vertical levels & $31 \sigma$ levels \\
Horizontal grid & Arakawa $\mathrm{C}$ grid \\
Time integration & Runge-Kutta third order time-splitting \\
& technique with $(\Delta \mathrm{t}=150 \mathrm{sec})$ \\
Radiation scheme & Dudhia's short wave/RRTM long wave \\
PBL scheme & ACM2, YSU, MYNN2.5 and QNSE \\
Convection & Grell-Devenyi, Betts Miller Janjic, and Kain-Fritsch \\
Microphysics & Kessler, Lin, Ferrier, WSM6 and Thompson \\
\hline
\end{tabular}

Better understanding of these physical processes along with the surrounding atmospheric flow is an essential factor for the movement and intensity of a tropical cyclone. So near real time prediction of such features of any cyclone is of great importance to avoid devastation.

Numerical weather prediction (NWP) is one of the best tools for this near real time prediction of such atmospheric phenomenon. It is a complex non-linear system represented by interaction of atmosphere and oceans with non-linear dynamics and physics. The use of NWP model for tropical cyclone studies started in the early 1960's and there have been a significant improvement in numerical weather prediction in the last three decades. Much of this improvement is due to computational resources, developments in numerical techniques, improved understanding of physical processes and improvements in observing systems, data assimilation and initialization. One such modelling system in present use is weather research and forecasting (WRF) with advanced research WRF (ARW) core and non-hydrostatic mesoscale model (NMM) core, which are designed to be flexible, state-of-the-art atmospheric simulation system.

The first attempt of using NWP model for TC studies was made by Kasahara (1961) through experiments with and without release of latent heat 
a)
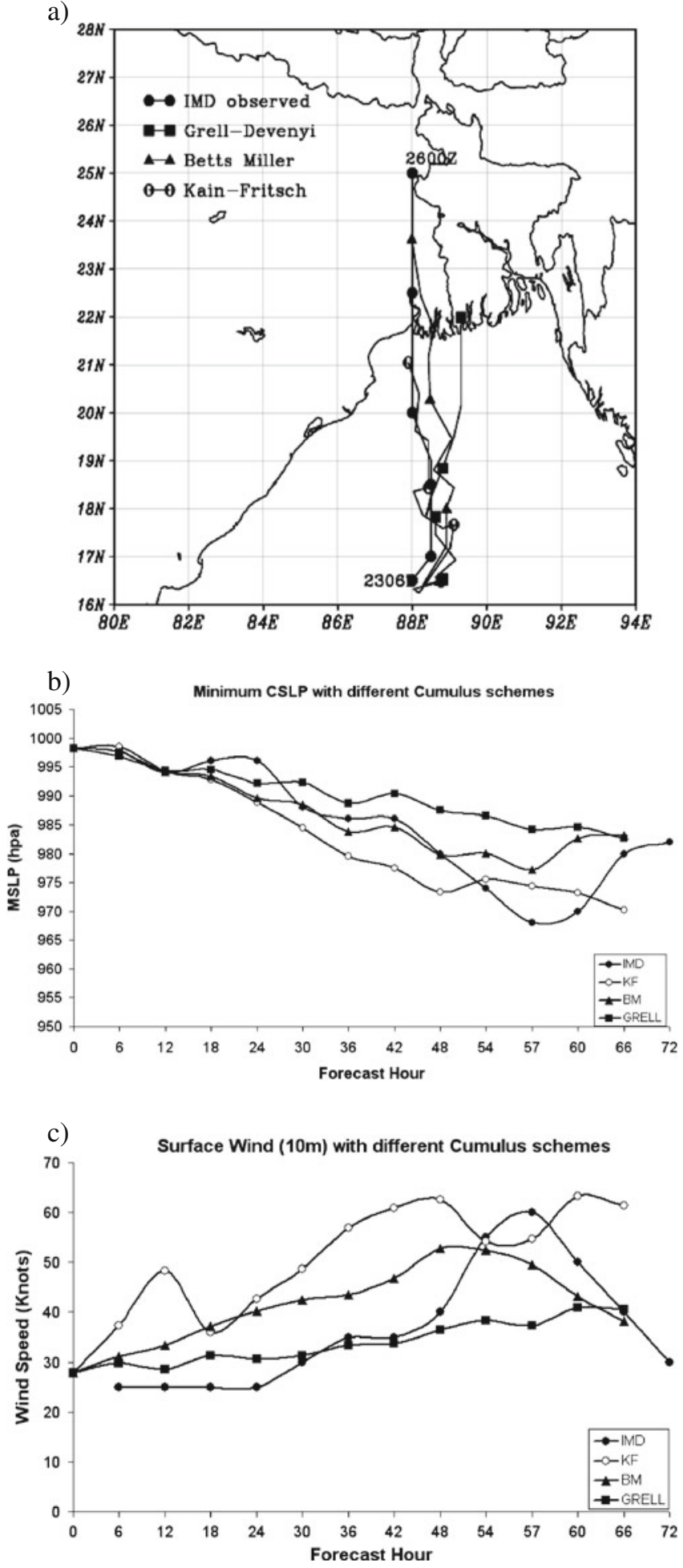

Figure 2. Comparison of model predicted (a) track of the system, (b) minimum CSLP (hpa) and (c) maximum surface wind (knots), with IMD observations for different convection parameterization schemes.

in a 19 level axi-symmetric models. Ogura (1964) first introduced the parameterization of cumulus convection in axi-symmetric models. Kuo (1965) proposed a cumulus parameterization scheme in which the vertical distribution of convective heating is related to the temperature difference between the clouds and their environments. Anthes and Hoke (1975) studied the effect of horizontal divergence and the latitudinal variation of the coriolis parameter on drift of a model hurricane. Holland (1980) made an analytical model of the wind and pressure profiles in hurricanes and in 1983, he studied the environmental interaction plus beta effect in tropical cyclone motion. Further in 1993 he published 'The global guide to tropical cyclone forecasting' (Holland 1993). Bhaskar Rao (1997) has used a 19 level axisymmetric, primitive equation hydrostatic model with a new convective parameterization scheme of Emanuel to simulate the evolution tropical cyclone from a weak initial vortex. Mohanty et al. (2004) simulated Orissa super cyclone using fifth generation mesoscale model (MM5) in order to evaluate the performance in simulating the track and intensity of the cyclone. Gilland and Rowe (2007) made a comparison of cumulus parameterization schemes in predicting warm season convection using WRF model. Pattanayak and Mohanty (2008) made a comparative study on MM5 and WRF (ARW and NMM) models in simulating the Mala tropical cyclone and observed that WRF ARW could simulate the intensity more reliably compared to MM5 and WRF NMM. From the past few decades with the developments in observational networks and NWP models good progress in forecasting tropical cyclone movement and intensity was achieved. However, still these systems pose challenges to forecasters by their erotic nature. Hence the present study is undertaken to simulate the severe cyclonic storm (SCS), AILA with the aim of studying the sensitivity in terms of intensity and movement of the system to three different physical processes in the WRF model, viz., convection, planetary boundary layer (PBL) and explicit cloud process. Further, the suitable combination of schemes for prediction of this severe cyclone is identified and used for analysis of different features of the system.

\section{System description}

Severe cyclonic storm AILA is one of the most devastating cyclones in the north Indian Ocean basin. The life cycle was about five days, i.e., from $22 \mathrm{nd}$ to 27th May 2009. The initial vortex of the storm formed over southeast Bay of Bengal (BOB) on 22nd May and was located as a depression with central sea level pressure (CSLP) of $998 \mathrm{hpa}$ at $0600 \mathrm{UTC}$ of $23 \mathrm{rd}$ near $16.5^{\circ} \mathrm{N}$ and $88.0^{\circ} \mathrm{E}$. The system moved gradually northward and intensified 
to deep depression with a decrease in CSLP to 992 hpa by 0300 UTC of 24th. Kalpana- 1 visible satellite imagery at this stage is shown in figure 1(a). It further intensified into a cyclonic storm by 12 UTC of the same day. Finally the system attained SCS intensity with a CSLP of $974 \mathrm{hpa}$ at $0600 \mathrm{UTC}$ of $25 \mathrm{th}$ and lay centered at about $21.5^{\circ} \mathrm{N}$ and $88.0^{\circ} \mathrm{E}$ (figure $1 \mathrm{~b}$ ). The cyclone had consistent northward movement with its landfall near east of Sagar Island between 0800 and $0900 \mathrm{UTC}$ at $21.5^{\circ} \mathrm{N}$ and $88.0^{\circ} \mathrm{E}$ with maximum sustaining winds of $100-110 \mathrm{kmph}$ and CSLP of $968 \mathrm{hpa}$. The system continued severe cyclonic intensity after landfall for 6 hours. Gradually it weakened into cyclonic storm by 1500 UTC of 25th near Gangetic West Bengal. It retained its intensity for 12 hours and continued northward movement. It then weakened into deep depression and finally to a low pressure (CSLP $992 \mathrm{hpa}$ ) by 0900 UTC on 26th. It became less marked by 27th May.

This consistent northward movement of the system throughout its track, rapid intensification just few hours before landfall and maintaining its cyclonic intensity for about 15 hours after landfall are the special features of this severe cyclone AILA. Prediction of these special features of the system is also attempted in the present work.

\section{Experimental design and data used}

In the present study WRF-ARW 3.1 modeling system is used to simulate AILA with different physical processes. This modelling system developed by the meso-scale and micro-scale meteorology (MMM) division of National Center for Atmospheric Research (NCAR), is a fully compressible, non-hydro static system of equations with complete coriolis and curvature terms. Model equations are in the mass-based terrain following sigma coordinate system and solved in Arakawa-C grid. RungeKutta third order time integration technique is used for model integration (William et al. 2008).
The model is designed for a single domain at a horizontal resolution of $27 \mathrm{~km}$ with 31 levels in the vertical and is integrated with the time step of $150 \mathrm{sec}$. This larger time step is chosen due to the robust dynamics of the WRF model which has the capability to run with nearly six times of the model horizontal resolution.

The initial and time-varying lateral boundary conditions are taken from the National Center for Environmental Prediction (NCEP) global forecast system (GFS) analysis available at a one-degree resolution. The model is integrated for 72 hours, starting from 0000 UTC on 23rd May 2009. Since the improvement in the movement and intensity of cyclones in the Bay of Bengal after assimilating local observational data through objective analysis is observed in our previous study (Gayatri Vani et al. 2011), in order to improve the model initial conditions the available observational data is assimilated into the model through objective analysis technique. In this technique, the observations are combined with the first guess field for better initialization of the atmospheric state in the model. There are several approaches in the formulation of objective analysis, namely successive correction methods, nudging methods, leastsquares methods and variational methods. They differ in that some are empirical, whereas others use statistical information about the observation and first guess filed error. In the present study the Cressman scheme of successive correction method is used. This technique assigns a circular radius of influence and gives weightage to observation based on distance of observation from grid point and corrects the first guess field in subsequent iterations. The detailed description of this technique can be found in ARW version 3 user guide (2012). The surface observations from Indian Space Research Organization (ISRO) automatic weather stations, atmospheric motion wind vectors derived (Kishtawal et al. 2009) from Kalpana-1 satellite (www.mosdac.gov.in) and radiosonde data provided by University of Wyoming (http://weather. uwyo.edu/upperair/sounding.html) are considered for objective analysis. The model topography is

Table 2. Landfall error, time of landfall error, peak values of CSLP and surface wind with different convection schemes.

\begin{tabular}{|c|c|c|c|c|c|c|}
\hline \multirow{3}{*}{$\begin{array}{l}\text { CP } \\
\text { schemes }\end{array}$} & \multicolumn{2}{|c|}{ Landfall error } & \multirow{2}{*}{\multicolumn{2}{|c|}{ Lowest SLP (hpa) }} & \multirow{2}{*}{\multicolumn{2}{|c|}{ Peak surface wind (knots) }} \\
\hline & \multirow{2}{*}{$\begin{array}{l}\text { Position } \\
(\mathrm{km})\end{array}$} & \multirow{2}{*}{$\begin{array}{l}\text { Time } \\
(\mathrm{hr})\end{array}$} & & & & \\
\hline & & & Predicted & Observed & Predicted & Observed \\
\hline GRELL & 141 & -15 & 982 & 968 & 41 & 60 \\
\hline $\mathrm{BM}$ & 47 & 00 & 977 & 968 & 53 & 60 \\
\hline $\mathrm{KF}$ & No landfall & No landfall & 970 & 968 & 63 & 60 \\
\hline
\end{tabular}


obtained from the USGS topography data at a resolution of 2 minute.

With the above discussed model configuration, three sets of experiments are conducted to study the sensitivity of convection, PBL and microphysics (MP) parameterization schemes. For these experiments four PBL schemes, viz., asymmetrical convective model version 2 (ACM) (Pleim 2007), Yonsei University (YSU) (Hong et al. 2006), MellorYamada Nakanishi and Nini Level 2.5 (MYNN) (Nakanishi and Niino 2004) and quasi normal scale elimination (QNSE) (Sukoriansky et al. 2006), three convection schemes Grell-Devenyi (GD) (Grell and Devenyi 2002), Betts-Miller-Janjic (BMJ) (Betts and Miller 1986; Janjic 1994, 2000) and Kain-Fritsch (KF) (Kain and Fritsch 1993; Kain 2004) and five MP schemes Kessler (KS) (Kessler 1969), Lin (LN) (Lin et al. 1983), Ferrier (FR) (Ferrier et al. 2002), WRF single moment 6 class scheme (WSM6) (Hong and Lim 2006) and Thompson (TP) (Thompson et al. 2004) are chosen. Initially, each experiment (e.g., convection schemes) is carried out by assuming and fixing two schemes each from other physics (e.g., PBL and $\mathrm{MP}$ ) as best schemes. Later, in course of experiments, if some other set of schemes (i.e., PBL and $\mathrm{MP}$ ) is found to be performing better than what we fixed in the previous, then the first experiment (convection Scheme) is repeated with this combination (i.e., PBL and MP) of schemes. In this way all the three experiments were carried out in trial and error method. Finally, the best combination of schemes from all the three experiments is chosen to study the characteristics of this cyclone. The detailed description of the configuration of the model used in the present study is presented in the table 1.

The observed intensity and the position of the severe cyclone are taken from the IMD for comparison with model results. The model predicted rainfall is compared with observed rainfall from tropical rainfall measuring mission (TRMM) Three-hourly products, which is the merged analysis of TRMM microwave imager, precipitation radar and rainguage observations carried out by National Aeronautics and Space Administration (NASA).

\section{Results and discussion}

For any cyclone, prediction of accurate position and time of landfall, lowest SLP and maximum wind at mature stage are generally considered to be important parameters to take the required safety measures. Hence in the present study, these a)

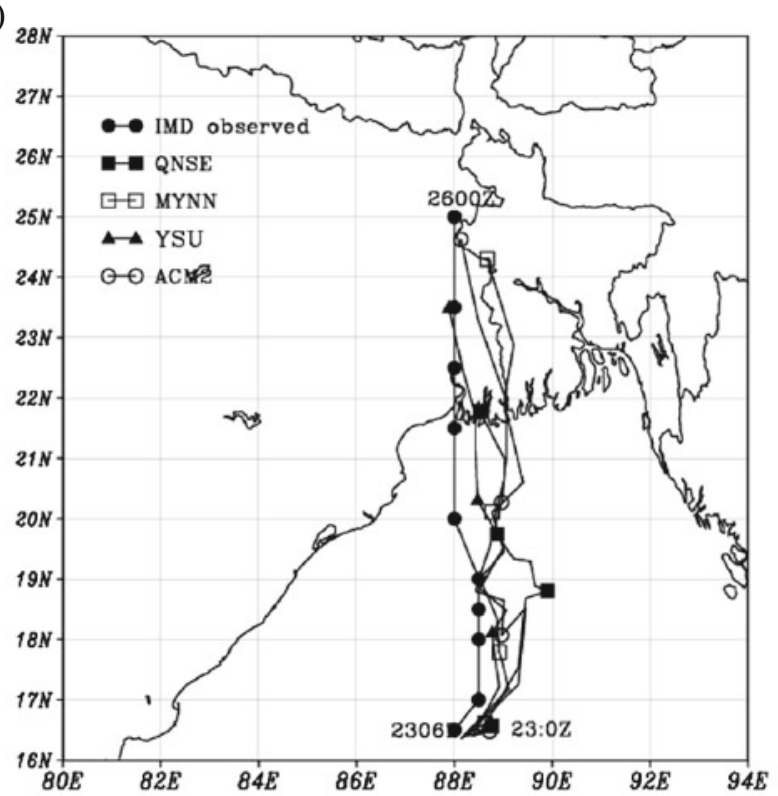

b)

Minimum CSLP with different PBL schemes

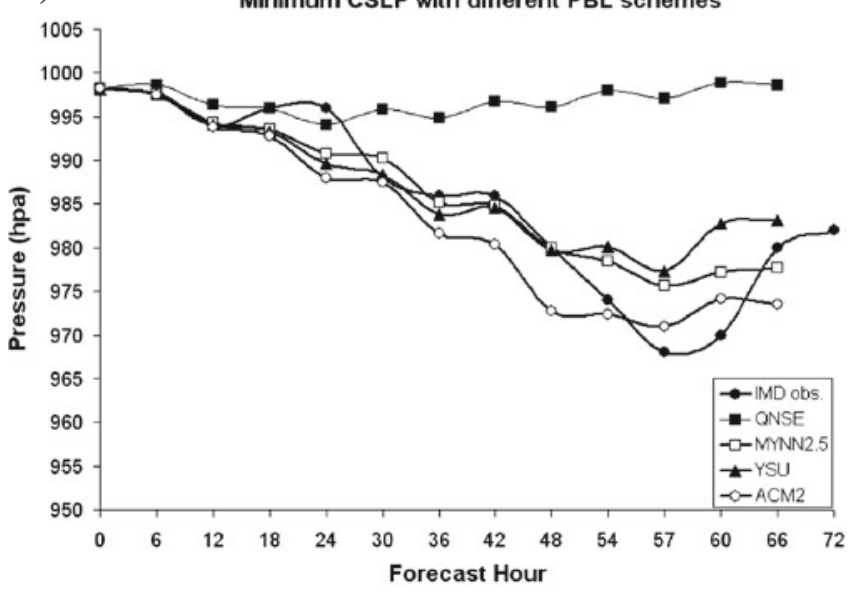

c)

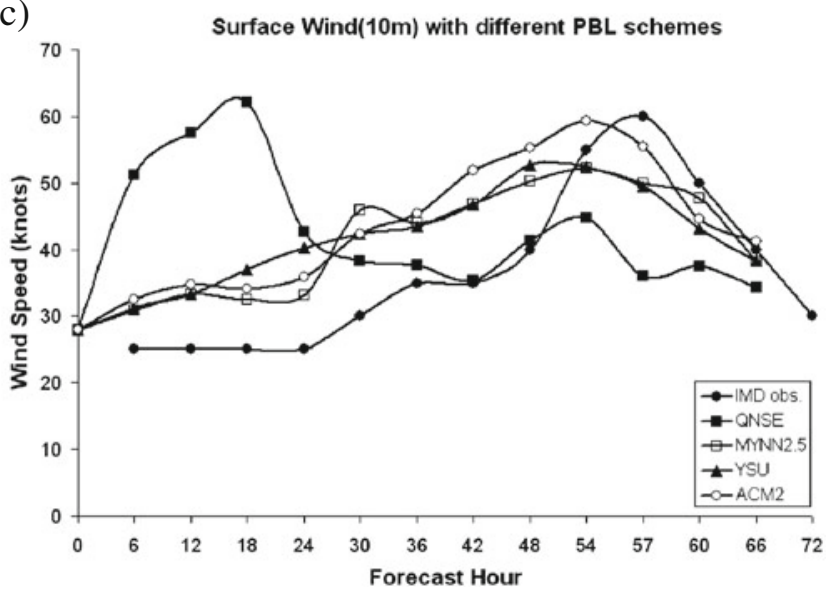

Figure 3. Comparison of model predicted (a) track of the system, (b) minimum CSLP (hpa) and (c) maximum surface wind (knots), with IMD observations for different PBL parameterization schemes.

parameters simulated by the model are considered and compared with observations to choose the best set of schemes. 


\subsection{Sensitivity experiments with convection schemes}

As discussed earlier, in each experiment two best schemes from other two experiments are fixed by trial and error method. In this section, results of the experiments conducted by fixing the best scheme from other two experiments, i.e., YSU for PBL and LN for explicit moisture and with different convection schemes (i.e., KF, BMJ and GD) are presented. Model simulated track positions with that of the IMD observed are shown in figure 2(a). The results show that all the three schemes simulated northward movement of the system. The track positions simulated with KF are in good coincidence with observed position but the predicted movement of the system is slow and no landfall is indicated in next 72 hours. In case of BMJ also the movement of the system is near to the observed with slight eastward deviation all through the 72 hours. Till 48 hrs, track predicted with GD scheme is exactly in coincidence with the IMD position but thereafter a deviation towards east is observed with landfall near Bangladesh at 00 UTC on 26th May.

Model simulated minimum central sea level pressure (CSLP) and maximum surface wind at $10 \mathrm{~m}$ level (MaxW) at every 6 -h interval are shown in figure $2(\mathrm{~b}$ and $\mathrm{c})$. The results indicate that of the three schemes, GD scheme showed less intensification of the system and strongest intensity is simulated by KF scheme with 970 hpa CSLP and 63 knots at 72 nd hour. But simulations with this scheme indicated that the system would continue to intensify until 72 hours and lay in oceanic region, unlike the other two schemes. Even though BMJ could not simulate accurate maximum intensity values, the pattern of variation of wind and CSLP at pre-deepening, deepening and fill up stages of the storm, is in agreement with observation. It simulated maximum surface wind of 53 knots and minimum CSLP of 977 hpa. So in total both movement and intensity of the cyclone showed their sensitivity to cumulus physics.
As already mentioned, for any cyclone, simulation of accurate landfall, time of landfall, lowest central pressure and maximum wind are important. The above parameters for different convection schemes are presented in table 2. From the tabulated values it is observed that the GD scheme, which uses multiple cumulus schemes and variants to get the average sounding profile to the model, shown large error in the track and underestimation of intensity. Adjustment of model sounding to a predetermined reference profile may have resulted in less amount of latent heat release and in-turn less pressure drop and wind intensity than observed in the case of BMJ scheme. On the other hand, KF scheme uses the CAPE that is present in the sounding to determine storm properties such as heating and moistening resulted in simulating intensity values near to observed, but it failed in the track prediction with slow movement of the system. As a whole BMJ performed better compared to other two schemes in simulating the track with least landfall error, no temporal error and with slight underestimation in intensity prediction.

\subsection{Sensitivity experiments with PBL schemes}

In this section, another set of experiments which uses different PBL schemes namely YSU, MYNN, QNSE and ACM by fixing the BMJ for convection and LN for microphysics scheme (best schemes from other two experiments) is presented. Simulated tracks of the cyclone with different $\mathrm{PBL}$ schemes (with QNSE, ACM and MYNN) indicate widespread dispersion towards east beyond $36 \mathrm{hr}$ (figure 3a). The track from the YSU experiment scheme also deviated between 36 and $48 \mathrm{hr}$ and again was near to the actual position during the integration progresses. QNSE experiment has indicated relatively slow movement of the system with landfall on 26th 0000 UTC. Although tracks from all the experiments deviate, YSU simulated with minimum landfall error.

Table 3. Landfall error, time of landfall error, peak values of CSLP and surface wind with different PBL schemes.

\begin{tabular}{|c|c|c|c|c|c|c|}
\hline \multirow{3}{*}{$\begin{array}{l}\text { PBL } \\
\text { schemes }\end{array}$} & \multicolumn{2}{|c|}{ Landfall error } & \multirow{2}{*}{\multicolumn{2}{|c|}{ Lowest SLP (hpa) }} & \multirow{2}{*}{\multicolumn{2}{|c|}{ Peak surface wind (knots) }} \\
\hline & \multirow{2}{*}{$\begin{array}{c}\text { Position } \\
(\mathrm{km})\end{array}$} & \multirow{2}{*}{$\begin{array}{c}\text { Time } \\
(\mathrm{hr})\end{array}$} & & & & \\
\hline & & & Predicted & Observed & Predicted & Observed \\
\hline $\mathrm{ACM}$ & 114 & -03 & 971 & 968 & 59 & 60 \\
\hline YSU & 47 & 00 & 977 & 968 & 53 & 60 \\
\hline MYNN & 118 & -03 & 975 & 968 & 52 & 60 \\
\hline QNSE & 71 & -15 & 997 & 968 & 62 & 60 \\
\hline
\end{tabular}


The predicted minimum CSLP and MaxW from these experiments show that with QNSE scheme there is an overestimation of winds initially and then an underestimation at the time of deepening period of the system. Simulation with ACM schemes resulted in 971 hpa minimum CSLP and MaxW of 59 knots. The pattern of variation of these parameters simulated with YSU and MYNN is nearer to the observed (figure $3 \mathrm{~b}$ and $\mathrm{c}$ ). Table 3 shows the landfall error, time error in landfall, minimum central pressure and maximum wind for this set of experiment. With the advantage of treating the entrainment process explicitly, the YSU scheme has simulated movement and intensity near to the observed values compared to other schemes. ACM, a first order closure scheme like YSU showed closer to observed values of intensity but failed in predicting track with high landfall error. Whereas the other two turbulent kinetic energy (TKE) closure schemes (MYNN and QNSE) showed moderate results.

\subsection{Sensitivity experiments with microphysics schemes}

This set of experiments were conducted by choosing the convection (BM) and PBL (YSU) schemes from the previous two experiments along with five different options for explicit moisture namely, KS, LN, WSM6, FR and TP microphysics schemes. All these experiments simulated the movement of the system close to the observed with lesser error until 48 hrs after which an eastward deviation was observed (figure 4a).

The minimum CSLP and intensity of the system with this set of experiments are shown in figure 4(b and c), respectively. The results indicate that all the schemes had overestimated CSLP and MaxW at pre-deepening period (up to $48 \mathrm{hrs}$ ) and underestimated in the deepening period. Except KS, all the other schemes well indicated the pattern of variation of CSLP and MaxW. Better results were obtained with LN scheme, which simulated minimum CSLP of $977 \mathrm{hpa}$ and maximum wind of 53 knots.

The landfall error, time of landfall error, minimum central pressure and maximum wind for this set of experiments is presented in table 4 . From the table it is observed that LN, WSM6 and TP showed better results with the advantage of including ice and mixed phase variables also in the model. KS and TP simulated more accurate landfall but underestimated the intensity values. However, relatively Lin performed better than the other four schemes for explicit moisture. As a whole it is observed that microphysical schemes a)
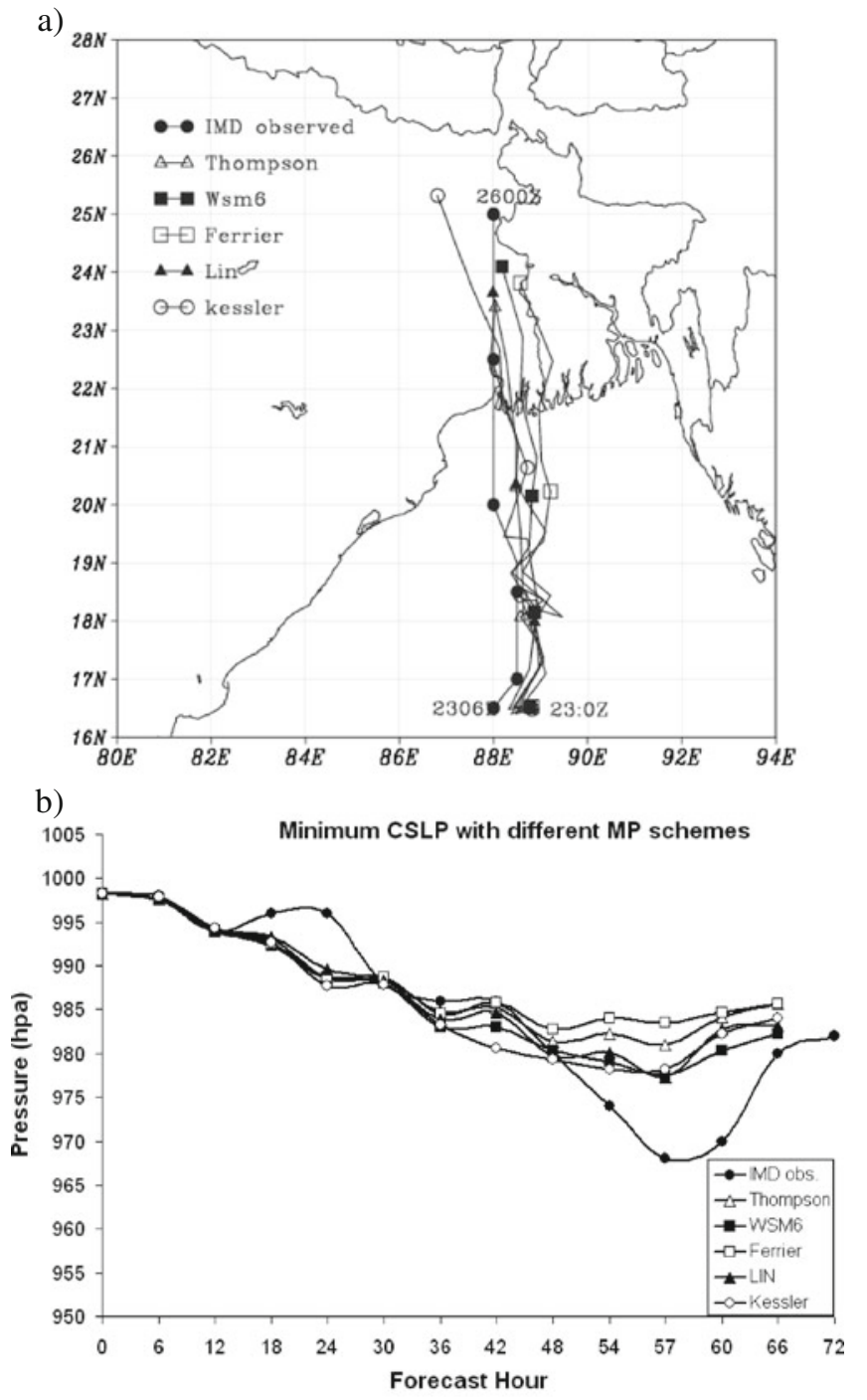

c) Surface Wind(10m) with different MP schemes

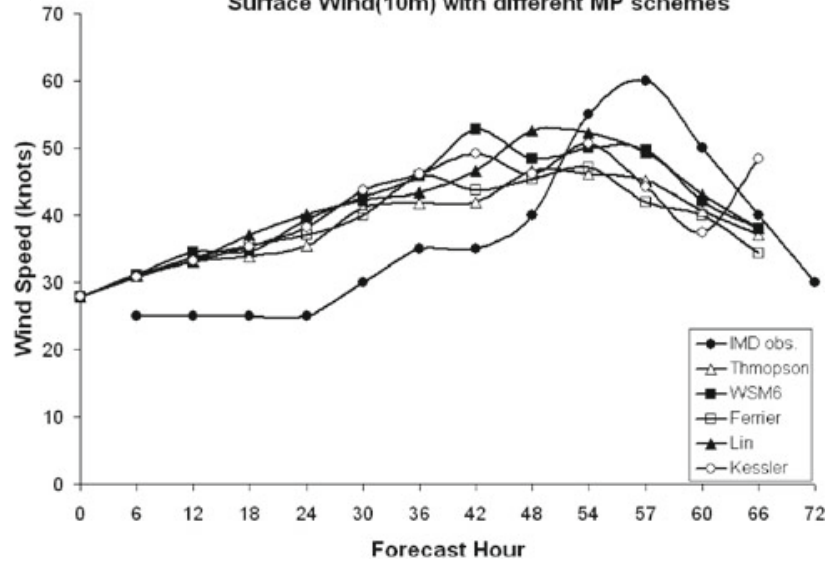

Figure 4. Comparison of model predicted (a) track of the system, (b) minimum CSLP (hpa) and (c) maximum surface wind (knots), with IMD observations for different microphysics parameterization schemes.

have less impact in simulating movement and intensity of the system, compared to other two physical processes. 
Table 4. Landfall error, time of landfall error, peak values of CSLP and surface wind with different MP schemes.

\begin{tabular}{|c|c|c|c|c|c|c|}
\hline \multirow{3}{*}{$\begin{array}{l}\text { MP } \\
\text { schemes }\end{array}$} & \multicolumn{2}{|c|}{ Landfall error } & \multirow{2}{*}{\multicolumn{2}{|c|}{ Lowest SLP (hpa) }} & \multirow{2}{*}{\multicolumn{2}{|c|}{ Peak surface wind (knots) }} \\
\hline & \multirow{2}{*}{$\begin{array}{l}\text { Position } \\
(\mathrm{km})\end{array}$} & \multirow{2}{*}{$\begin{array}{l}\text { Time } \\
\text { (hr) }\end{array}$} & & & & \\
\hline & & & Predicted & Observed & Predicted & Observed \\
\hline KESSLER & 32 & +06 & 978 & 968 & 51 & 60 \\
\hline LIN & 47 & 00 & 977 & 968 & 53 & 60 \\
\hline FERIER & 100 & -03 & 983 & 968 & 47 & 60 \\
\hline WSM6 & 69 & -03 & 977 & 968 & 53 & 60 \\
\hline THOMPSON & 34 & -03 & 981 & 968 & 47 & 60 \\
\hline
\end{tabular}

All the three sets of experiments clearly indicated the sensitivity of movement to all parameterization schemes. However, the movement is more sensitive to the cumulus physics compared to microphysics and PBL, which is in agreement with the results of previous studies (Bhaskar Rao and Hari Prasad 2007). This indicates that movement of the system mainly depends on the mass fluxes and convective scale vertical velocities that in turn depends on strength of convergence (CISK) and radial pressure gradient in the system. So choice of the right cumulus scheme plays an important role in predicting the movement of the system. PBL and convection processes play a major role in the intensification of the system whereas it is less sensitive to microphysics. This sensitivity to PBL proves that the energy transfer in boundary layer play a crucial role in feeding the system. Convection process includes latent heat flux at convective scales and hence is important in simulating the intensity of the system. Hence PBL and convection should be precisely defined and parameterized into the numerical models for better simulation of the intensity of the system. It is also observed that BMJ for convection, YSU for PBL and LN for microphysics simulated the system close to the observed track and intensity. There is no temporal error in predicting the landfall but a positional error of $47 \mathrm{~km}$ is observed in predicting the landfall. A least difference of 9 hpa was observed in the predicted lowest SLP in comparison with IMD observed values. The maximum winds predicted by the model was 53 knots against the observed of 60 knots. The above values indicate the accurate prediction of the cyclone with this set of schemes compared to the other sets.

\subsection{Features of the system}

With the above set of best suite schemes different features of the system at the mature stage $(0900$ UTC of 25th May 2009) like, wind at different pressure levels (figure 5), sea level pressure (SLP) and pressure drop (figure 6) and vertical cross section of the system are discussed in this section. The horizontal structure of the wind at 850, 500 and $300 \mathrm{hpa}$ of the system are examined. The wind pattern at 850 hpa level indicated a well-established eye and eye wall with core winds exceeding 60 knots in the northeastern sector of the system. Tilting of vertical axis of the system towards west and decreasing strength of wind with height is observed in the wind pattern from 850 to $500 \mathrm{hpa}$. The wind at $300 \mathrm{hpa}$, which has more of southerly component, might have acted as a steering current to move the system in north direction all through its journey.

The distribution of SLP along with wind barbs at $850 \mathrm{hpa}$ is presented in figure 6(a). The cyclone has attained maximum intensity with a minimum SLP of 977 hpa and maximum wind of 53 knots. With this severe cyclonic intensity, the system has crossed the coast near Sagar Island on 25th 09 UTC and maintained cyclonic storm intensity till 26th May 00 UTC (about 15 hours) as simulated by the model. This may be attributed to the movement over the Gangetic delta region where abundant moisture might have supported the system for quite long time. A maximum pressure fall of nearly $18 \mathrm{hpa}$ was predicted in $24 \mathrm{hr}$ between 0900 UTC of 24th and 25th May (figure 6b), which was exactly in coincidence with IMD observed value of $18 \mathrm{hpa}$ (986-968 hpa).

To study the vertical structure of the system along the center of the cyclone, a horizontal line $\mathrm{AB}$ is drawn along the latitude of the center $\left(21.5^{\circ} \mathrm{N}\right)$ just before the landfall. The vertical cross section of the scalar wind, vertical velocity and reflectivity along that horizontal axis are shown in figure $7(\mathrm{a}, \mathrm{b}, \mathrm{c})$. A calm wind region at the center of the cyclone with horizontal speeds of 5-10 knots is observed. A tilting in this calm region is observed above $500 \mathrm{hpa}$, which indicates the tilting in the vertical axis of the system. The deeper and stronger winds are observed in the eastern sector of the cyclone compared to western sector. Winds 
a)

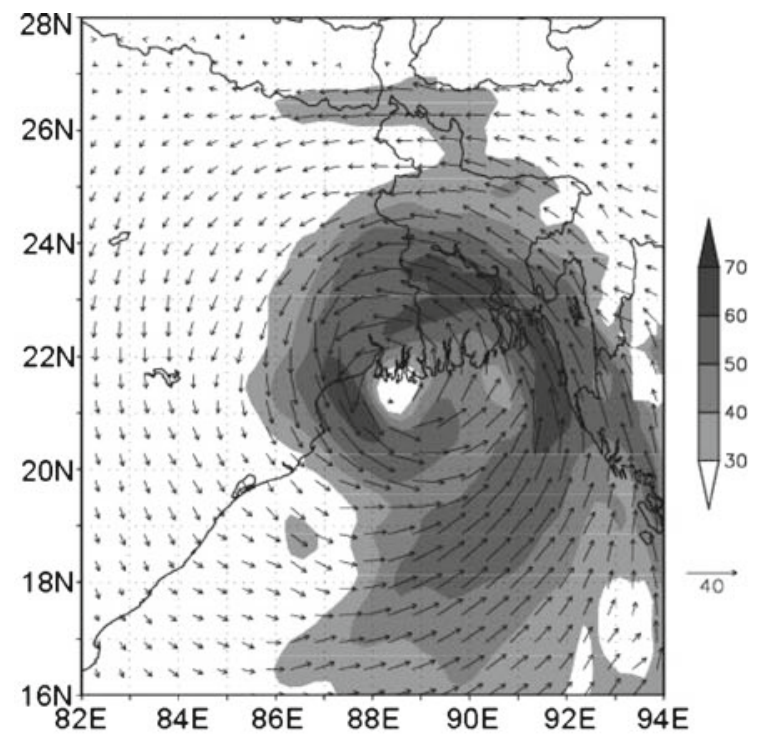

b)

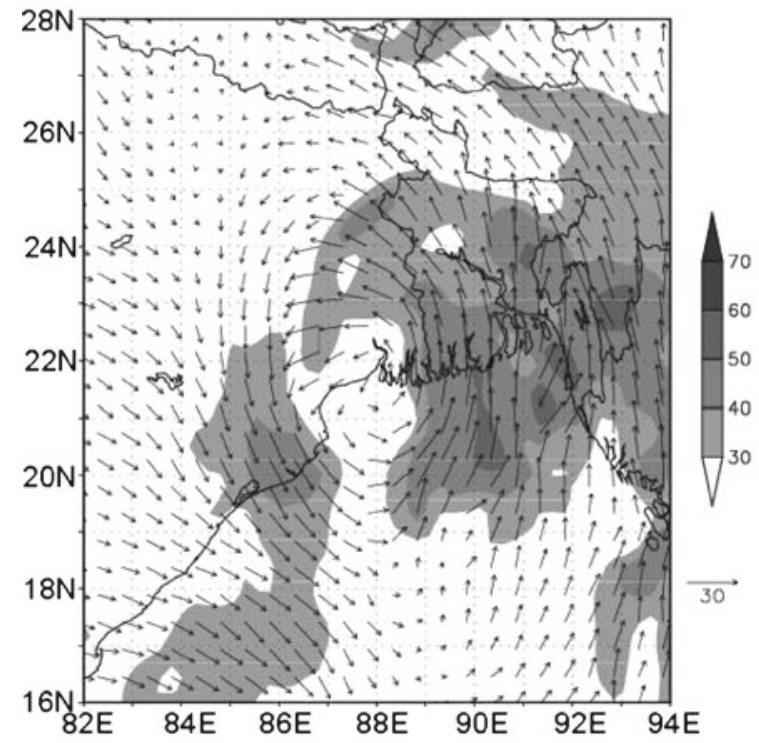

c)

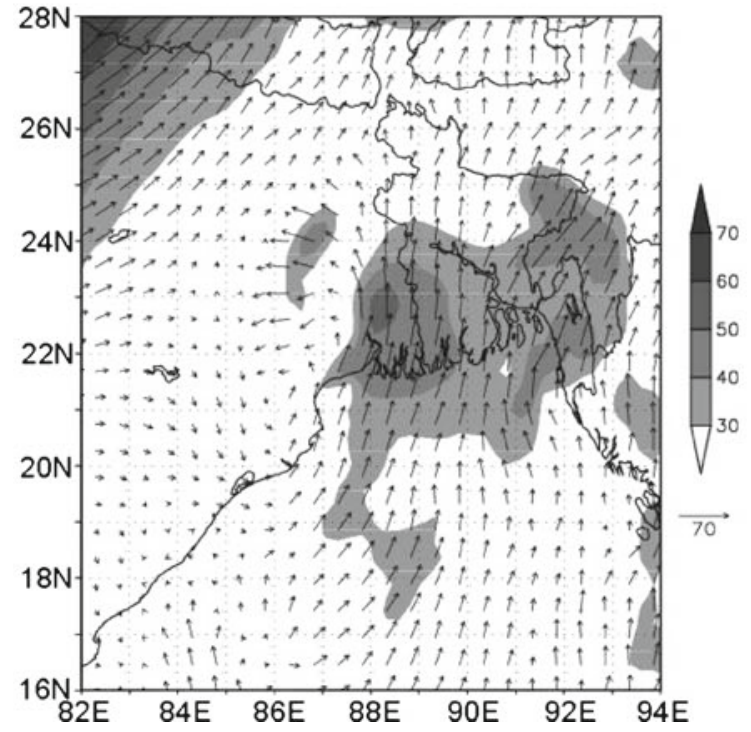

Figure 5. Model predicted (a) $850 \mathrm{hpa}$, (b) $500 \mathrm{hpa}$ and (c) $300 \mathrm{hpa}$ level wind (knots) structure at mature stage (0900 UTC of 25th May 2009). of cyclonic intensity ( $>34$ knots) extended up to $500 \mathrm{~km}$ in the horizontal and $12 \mathrm{~km}$ in the vertical in the eastern sector and $200 \mathrm{~km}$ horizontal extent and $5 \mathrm{~km}$ vertical extent in the western sector. Cross sectional plot of vertical velocity showed more intensified updrafts in the upper levels with values exceeding $2.4 \mathrm{~m} / \mathrm{s}$ in the eastern sector (figure 7b). Reflectivity factor indicated maximum values of the order of $40 \mathrm{dbz}$ at the eye wall region where extensively large convective cloud towers exists (figure 7c).

The spatial distribution of model simulated 24-hour accumulated rainfall at 0000 UTC of 24, 25 and 26th May 2009 along with corresponding TRMM observations are shown in figure 8. On 24th May 0000 UTC, model simulated a large amount of rainfall in north-eastern (NE) and south-western (SW) sector of the system, whereas TRMM observed rainfall is in the

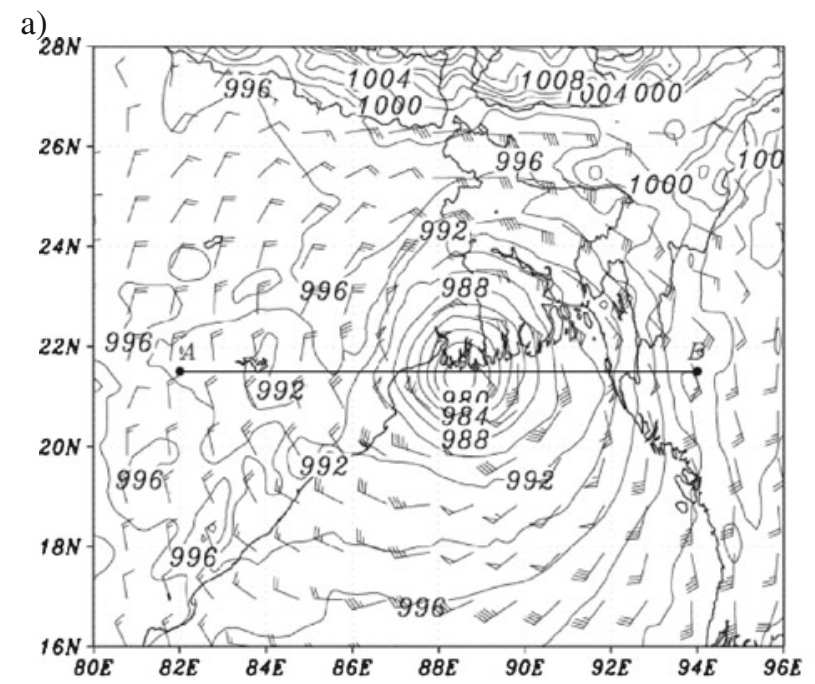

b)

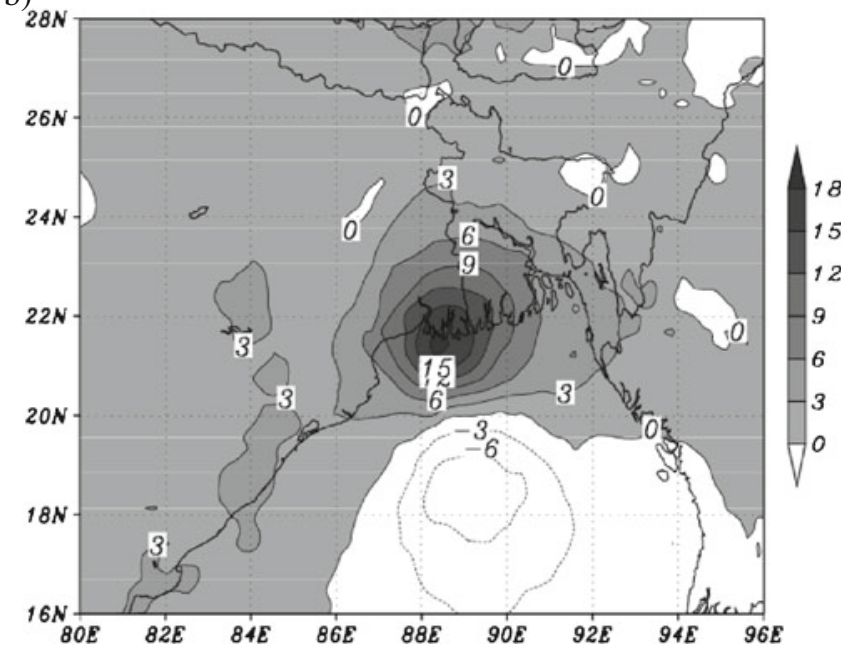

Figure 6. (a) CSLP (hpa) along with 850 hpa wind and (b) $24 \mathrm{hr}$ pressure drop (hpa), at mature stage (25th May 09 UTC). 


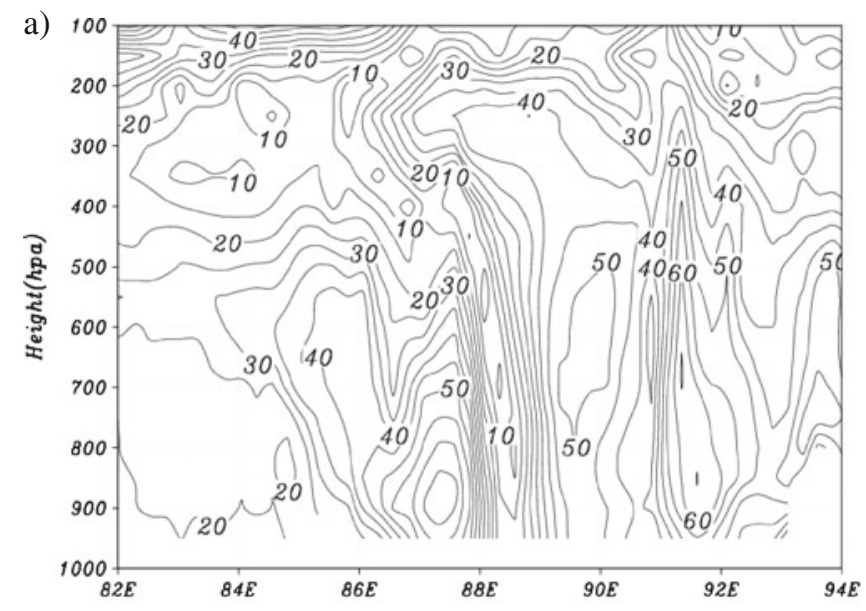

b)

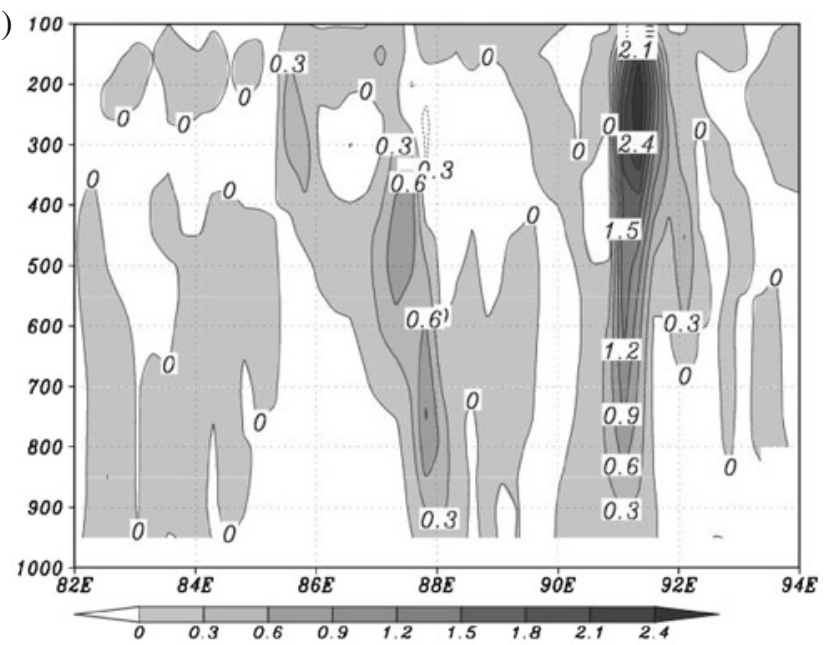

c)

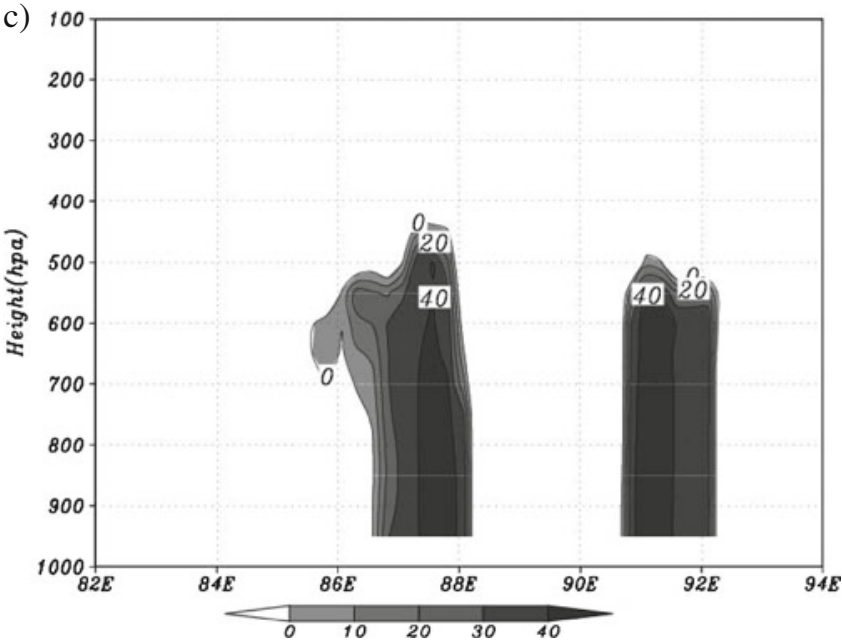

Figure 7. Vertical cross-section along the line AB of figure 6 . (a) Horizontal wind speed $(\mathrm{m} / \mathrm{sec})$, (b) vertical velocity (W) $(\mathrm{m} / \mathrm{sec})$ and $(\mathbf{c})$ reflectivity $(\mathrm{dbz})$.

SW sector with less amount in the NE sector (figure 8a, d). At 0000 UTC of 25th May, model simulated a maximum amount of rainfall exceeding $200 \mathrm{~mm}$ in the northwest sector near to north coastal Orissa region, which is in good agreement with the TRMM observed. But model overestimated in the south BOB (figure 8b, e). At 0000 UTC of 26th May, model simulated large rainfall amounts over north Orissa, West Bengal and east Bangladesh region which is in good coincidence with TRMM rainfall spatially but quantitatively model overestimated the amount of rainfall. And model simulated a good amount of rainfall in east central BOB but relatively less amount of rainfall was observed (figure 8c, f).

\section{Summary and conclusions}

In the present article, the sensitivity of movement and intensity of severe cyclone AILA (23rd May 2009) to three major physical processes namely convection, $\mathrm{PBL}$ and MP in the WRF model are investigated. Series of experiments were carried out for three physical processes. From each experiment one best scheme is selected based on the accuracy of prediction of position, time and peak intensity of the cyclone. From these experiments it is found that the movement of the cyclone is more sensitive to the cumulus parameterization. PBL and convection processes play a major role in the intensification of the system whereas it is less sensitive to MP. The combination of BMJ from convection, YSU from PBL and LN from MP processes showed better results compared to other combinations from all experiments. This may be attributed to accurate treatment of deep convection profile in BMJ, good representation of sub-grid scale fluxes due to eddy transport in YSU and accurate representation of number density of microphysical variables in $\mathrm{LN}$ schemes.

Further different horizontal and vertical features of the system at the mature stage (0900 UTC of 25th May 2009) are analyzed from the simulation of best combination schemes. The complete northward movement of the system throughout the life period and the consistent cyclonic storm intensity of the system, until $15 \mathrm{hrs}$ after the landfall, which are the special feature of this cyclone, could be well simulated by the model. Vertical cross section of strong core winds along with westward tilting of the cyclone, vertical velocities and magnitude of reflectivity in the eye wall are also well captured by the model. The peak intensity of 53 knots MaxW and 977 hpa CSLP were predicted against IMD observed values of 60 knots and $968 \mathrm{hpa}$, respectively. Spatial comparison of model predicted $24 \mathrm{hr}$ accumulated rain with TRMM rainfall indicated that model could simulate the sector of maximum precipitation reasonably well but with a slight quantitative overestimation. 
a)

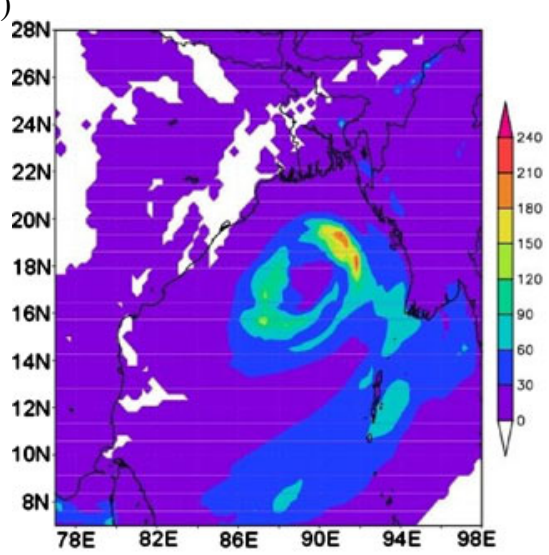

d)

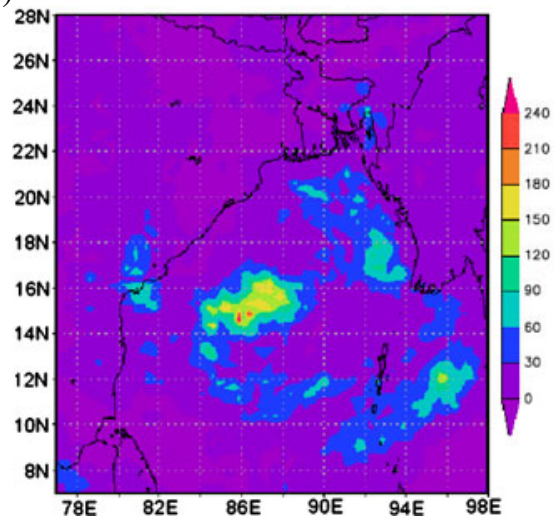

b)

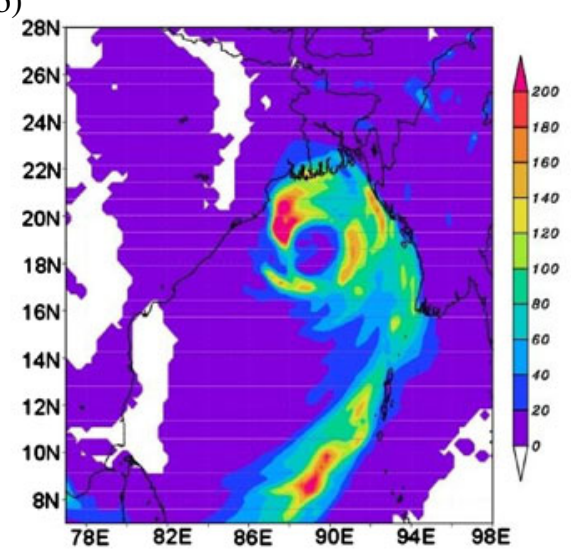

e)

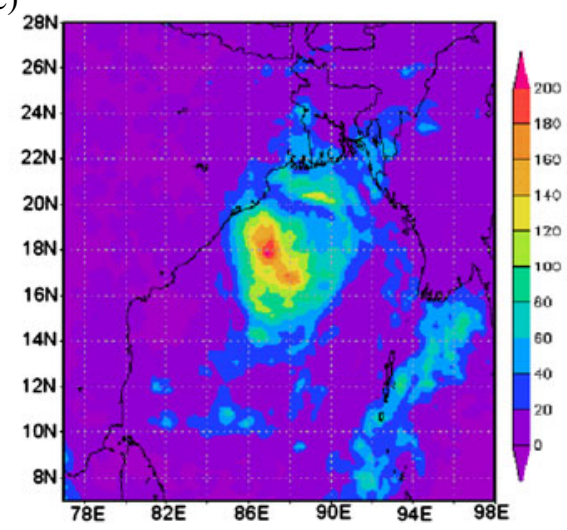

c)

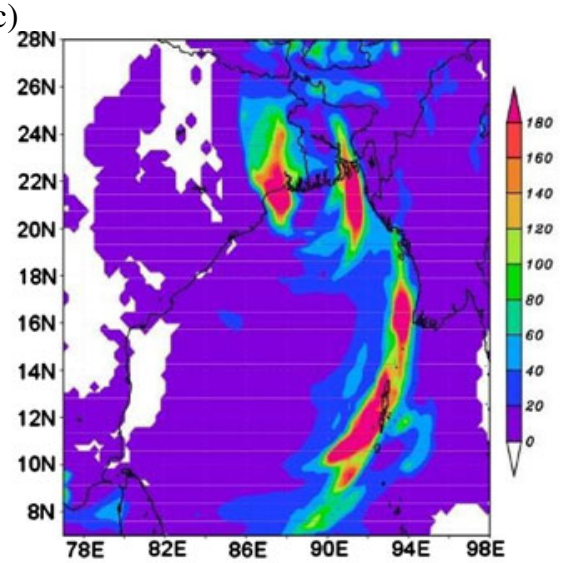

f)

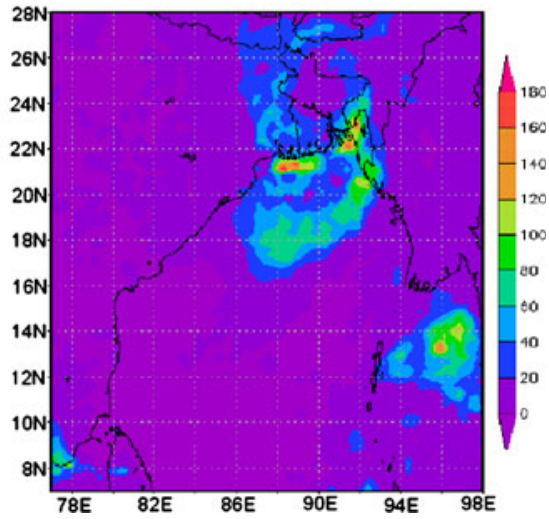

Figure 8. $24 \mathrm{hr}$ accumulated rain (mm) from the model (above) and TRMM observation (below) on 24th $0000 \mathrm{UTC}(\mathbf{a}, \mathbf{d})$, 25th 0000 UTC $(\mathbf{b}, \mathbf{e}), 26$ th 0000 UTC $(\mathbf{c}, \mathbf{f})$.

In the present study, sensitivity tests are carried out for one cyclone with the available computational facility. Similar case studies for different cyclones over $\mathrm{BOB}$ are to be made to fix the best suite of schemes that would resolve convection, PBL and microphysical processes more precisely in the model for this region. This could be carried as future part of the work to supplement these results.

\section{Acknowledgements}

The authors are thankful to ISRO authorities for allowing them to carry out research under Prediction of Regional Weather with Observational Meso-Network and Atmospheric Modelling (PRWONAM) project. The satellite derived winds and Automatic Weather Station data provided by MOSDAC, SAC and the radiosonde data provided by University of Wyoming are also acknowledged. They authors also owe thanks to India Meteorological Department for providing the observational data sets during the cyclone. The precipitation estimates provided by TRMM is highly acknowledged. They thank the anonymous reviewers, whose suggestions have resulted in substantial improvement of the paper.

\section{References}

Anthes R A and Hoke J A 1975 The effect of horizontal divergence and the latitudinal variation of the coriolis parameter on drift of a model hurricane; Mon. Weather Rev. $103757-763$.

ARW Version 3 modeling system user's guide, April 2012, Meso scale \& Microscale Meteorological Division, NCAR.

Betts A K and Miller M J 1986 A new convective adjustment scheme. Part II: Single column test using GATE wave, BOMEX, ATEX, and Arctic air mass data sets; Quat. J. Roy. Meteorol. Soc. 112 693-709.

Bhaskar Rao D V 1997 Tropical simulation with Emanuel's convection scheme; Mausam 48 113-112.

Bhaskar Rao D V and Hari Prasad D 2007 Sensitivity of tropical cyclone intensification to boundary layer and convective processes; Nat. Hazards 41 429-445.

Ferrier B S, Jin Y, Lin Y, Black T, Rogers E and DiMego G 2002 Implementation of a new grid-scale cloud and precipitation scheme in the NCEP Eta model; Preprints, 15th Conf. on NWP, San Antonio, Am. Meteorol. Soc., pp. 280-283.

Gayatri Vani D, Rambabu S, Rajasekhar M, Rama G V, Apparao B V and Ghosh A K 2011 Analysis of MM5 predictions at Sriharikota during north east monsoon 2008; J. Earth Syst. Sci. 120 755-771. 
Gilland E K and Rowe C M 2007 A comparison of cumulus parameterization schemes in the WRF model; 21st Conference on Hydrology.

Gray W M 1968 Global view of the origin of the tropical disturbance and storms; Mon. Weather Rev. 96 669-700.

Grell G A and Devenyi D 2002 A generalized approach to parameterizing convection combining ensemble and data assimilation techniques; Geophys. Res. Lett. 29 38-1-4.

Holland G J 1980 An analysis model of the wind and pressure profiles in hurricanes; Mon. Weather Rev. 108 $1212-1218$

Holland G J (ed.) 1993 The global guide to tropical cyclone forecasting WMO/TD-560; World Meteorological Organization, Geneva, 342p.

Hong S-Y and Lim J-O J 2006 The WRF Single-Moment 6Class Microphysics Scheme (WSM6); J. Korean Meteorol. Soc. 42 129-151.

Hong S Y, Noh Y and Dudhia J 2006 A new vertical diffusion package with an explicit treatment of entrainment processes; Mon. Weather Rev. 121 589-603.

Janjic Z I 1994 The step-mountain eta coordinate model: Further development of convection, viscous sublayer and turbulence closure schemes; Mon. Weather Rev. 122 927-945.

Janjic Z I 2000 Comments on 'Development and evaluation of convection scheme for use in climate models'; J. Atmos. Sci. 573686.

Kain J S 2004 The Kain-Fritsch convection parameterization: An update; J. Appl. Meteorol. 43 170-181.

Kain J S and Fritsch J M 1993 Convective parameterization for mesoscale models: The Kain-Fritsch scheme. The representation of cumulus convection in numerical models; Meteorol. Monogr. Am. Meteorol. Soc. 46 165-170.

Kasahara A 1961 A numerical experiment on the development of a tropical cyclone; J. Meteorol. 18 259-282.

Kessler E 1969 On the distribution and continuity of water substances in atmospheric circulation; Meteorol. Monogr. 3284.
Kishtawal C M, Deb S K, Pal P K and Joshi P C 2009 Estimation of atmospheric motion vectors from Kalpana-1 imagers; J. Appl. Meteorol. Climatol. 48 2410-2421.

Kuo H L 1965 On the formation and intensification of tropical cyclones through latent heat release by cumulus convection; J. Atmos. Sci. 22 40-63.

Lin Y-L, Farley R D and Orville H D 1983 Bulk parameterization of the snow field in a cloud model; J. Climate. Appl. Meteorol. 22 1065-1092.

Mohanty U C, Mandal M and Raman S 2004 Simulation of Orissa super cyclone (1999) using PSU/NCAR mesoscale model; Nat. Hazards 31 373-390.

Nakanishi M and Niino H 2004 An improved Mellor-Yamada level 3 model with condensation physics: Its design and verification; Bound. Layer Meteorol. 112 1-31.

Ogura Y 1964 Frictionally controlled, thermally driven circulation in a circular vortex with application to tropical cyclones; J. Atmos. Sci. 21 610-621.

Pattanayak S and Mohanty U C 2008 A comparative study on performance of MM5 \& WRF models in simulation of tropical cyclone over Bay of Bengal; Nat. Hazards 31 391-414.

Pleim J E 2007 A combined local and non-local closure model for the atmospheric boundary layer. Part: Model description and testing; J. Appl. Meteorol. Climatol. 46 $1383-1395$.

Skamarock W C, Klemp J B, Dudhia J, Gill D O, Barker D M, Duda M G, Huang X-Y, Wei-Wang and Powers J G 2008 A description of the Advanced Research WRF, NCAR technical note.

Sukoriansky S, Galperi B and Perov V 2006 A quasi-normal scale elimination model of turbulence and its application to stably stratified flows; Nonlinear Process. Geophys. 13 9-22.

Thompson G, Rasmussen R M and Manning K 2004 Explicit forecasts of winter precipitation using an improved bulk microphysics scheme. Part I: Description and sensitivity analysis; Mon. Weather Rev. 132 519-542. 